\title{
Information systems frontiers editorial December 2012
}

\author{
R. Ramesh • H. Raghav Rao
}

(C) Springer Science+Business Media New York 2012

Information Systems Frontiers (ISF) has crossed its first decade. We would like to thank all the Advisory Editors, the Executive Editors, the special issue editors and the various referees from across the world and of course Springer, the publishers, who have made this journal a success. In this last issue of 2012, ISF brings to you, nine articles which span the various topics at the frontiers of information systems.

The lead article by Nobel Laureate, Arrow (2012) is a thought piece on economic theory and the financial crisis. In this article, Profesor Arrow probes the role of the market in allocating resources. He suggests that the failure of markets for various kinds of derivative securities to perform properly is an essential element of the current financial crisis. Financial crises are not a new phenomenon and have been recognized by economists from John Stuart Mill (1848) onwards. Professor Arrow starts with the neoclassical general equilibrium framework, and seeks to identify a possible point at which it fails to supply a coherent theory of securities markets and so might possibly lead to some understanding of the repeated crises of the financial system underlying the development of capitalism. The article also touches upon one of the most important innovations in economic theory in the last 50 years-asymmetric information and points out that the presence of asymmetric information creates difficulties with the allocation of risks through the market. Professor Arrow argues that information is of the utmost importance in making economic decisions, especially when it comes to securities or other assets whose value depends on events that are yet unknown. Finally Professor Arrow discusses the issues of inefficient incentives and their

R. Ramesh·H. R. Rao $(\bowtie)$

SUNY Buffalo, Buffalo, NY, USA

e-mail: mgmtrao@gmail.com

H. R. Rao

Sogang University, Seoul, South Korea impact on the financial crisis and concludes with some policy implications.

The second article by Professors Zo et al. (2012) focuses on end-to-end reliability of service oriented applications. The paper focuses on reliability issues associated with applications developed within service oriented architecture. It develops a measure for deriving end-to-end application reliability. It further develops a model to help select appropriate services for tasks in the business process which accommodate the redundant and overlapping functionality of available services and planned redundancy in task support. A genetic algorithm approach is adopted to select promising services to assemble the application using endto-end reliability as the criterion of interest. The paper concludes with an application to a real-world business process.

Professors Chunlin Li and Layuan Li develop an efficient resource allocation for maximizing benefit of users and resource providers in ad hoc grid environment (2012). The paper proposes an efficient resource allocation scheme for grid computing marketplace where ad hoc grid user agents can buy usage of memory and CPU from grid resource providers. The agents goal is to obtain optimized quality of service to accomplish their tasks on time within a given budget, and achieve profit maximization. The paper combines perspectives of adhoc grid users as well as resource providers. Simulations are conducted to compare the performance of the algorithms with related work.

The fourth article, FAST: Fundamental Analysis Support for Financial Statements: Using semantics for trading recommendations (2012) is by Professors Alejandro Rodríguez-González, Ricardo Colomo-Palacios \& Fernando Guldris-Iglesias, Juan Miguel Gómez-Berbís and Angel García-Crespo. The authors present a real trading system that has been developed using semantic technologies. These enable the definition of schemes that can be used for storing financial information, which, in turn, can be easily accessed and queried. Additionally, they incorporate 
inference capabilities in their reasoning engines that enable the generation of a set of rules supporting the investment analysis process.

Applying ontology-based blogs to detect information system post-development change request conflicts (2012) by Professors Chi-Lun Liu and Heng-Li Yang follows. This design science article proposes an ontology-based blog for automatically discovering conflicts in the extended use-case models of requests from users. The proposed approach applies ontologies to represent domain knowledge. A set of rules are used to detect conflicts. The authors developed a prototype and invited two companies to evaluate it. Usage feedback opinions about ontology-based blog from two companies indicated their usefulness. The ontology-based blog is a relatively new approach which bridge requirements blogs with a formal and machine interpretable representational model. The automatic conflicts detection capability of the ontology-based blog can reduce the labor cost in requirements analysis phase.

Professors Probir Kumar Banerjee and Louis C. Ma, write about Routinisation of B2B E-commerce by small firms: A process perspective (2012). They probe deeper into the routinisation phenomenon and investigate the process in a bid to understand 'when' and 'why' certain technology, organization and environmental factors become crucial determinants at different stages of the routinisation process. The context of their study is integration of B2B e-markets by four small firms. Their findings from interpretive case studies indicate that changes in organizational characteristic (such as IT infrastructure), environmental characteristics (such as e-business usage in the industry), and perceptions of e-business (risk and benefit) over time influenced movement along the routinisation trajectory. Also, contrary to the independent effects of the organization, environment and technology characteristics assumed in prior research, they find that it is the interaction effect of the three factors that determines initial attitude, initial usage and continued usage. Based on their findings they develop a process model of e-business routinisation and discuss the theoretical and practical implications.

The seventh article on entrepreneurship, knowledge integration capability, and firm performance: An empirical study (2012) is by Professors Yong Jin Kim, Seokwoo Song, V. Sambamurthy and Young Lyoul Lee. In their study, they explore the effect of entrepreneurship on organizational performance through knowledge integration capability. Their research model depicts the firm as a knowledge integration institution that produces its offerings through specialized knowledge integration capability that consists of learning culture, knowledge management process, and information technology capability. The results show a strong support for the relationship between entrepreneurship and knowledge integration capability. They also found that the effect of entrepreneurial activities on firm performance was mediated by knowledge integration capability.

Professors K. Reddy, H. S. Venter and M. S. Olivier delve into using time-driven activity-based costing to manage digital forensic readiness (DFR) in large organizations (2012). In this paper they show that the relatively new cost system, time-driven activity-based costing (TDABC), can be used to determine the cost of implementing and managing activities required for DFR. They show through analysis and simulation that the cost information from a TDABC model can be used for such decisions. They also discuss some of the factors that ought to be considered when implementing or managing the use of TDABC in a large organisation.

The final, ninth article is on Choice of governance mechanisms to promote information sharing via boundary objects in the disaster recovery process (2012) by Professors Barry A. Cumbie and Chetan S. Sankar. This paper looks at the IT governance mechanisms used to promote information sharing via shared boundary objects in the disaster response and recovery process. A longitudinal, descriptive case study relates the experiences of a community of disaster recovery stakeholders from a coastal region as they work together to share digital geospatial data on the community's physical utility infrastructure.

We would also like to extend our congratulations to Professor Dr. Torsten J. Gerpott of the Mercator School of Management, University Duisburg-Essen for the selection of his paper in Information Systems Frontiers as one of the five Best Publications of 2011, as recognized by AIS, its senior scholars, and ICIS. Information Systems Frontiers 13 (4): 561-578 (2011) (Determinants of self-report and system-captured measures of mobile Internet use intensityAn empirical investigation of common method bias among German mobile communications customers) (2011).

Last, but not least, thanks to all our readers for supporting Information Systems Frontiers. Wishing you all a very happy holiday season and greetings for a happy new year 2013 .

\section{References}

Arrow, K. J. (2012). "Economic theory and the financial crisis". Information Systems Frontiers, 14(5).

Banerjee, P. K., \& Ma, L. C. (2012). "Routinisation of B2B Ecommerce by small firms: A process perspective". Information Systems Frontiers, 14(5).

Cumbie, B. A., \& Sankar, C. S. (2012). "Choice of governance mechanisms to promote information sharing via boundary objects in the disaster recovery process". Information Systems Frontiers, 14(5).

Gerpott, T. J. (2011). Determinants of self-report and system-captured measures of mobile Internet use intensity-an empirical investigation 
of common method bias among German mobile communications customers. Information Systems Frontiers, 13(4), 561-578.

Kim, Y. J., Song, S., Sambamurthy, V., Lee, Y. L. (2012). "Entrepreneurship, knowledge integration capability, and firm performance: An empirical study". Information Systems Frontiers, 14(5).

Li, C., \& Li, L. (2012). An efficient resource allocation for maximizing benefit of users and resource providers in ad hoc grid environment. Information Systems Frontiers, 14(5).

Liu, C-L., \& Yang, H-L. (2012). "Applying ontology-based blog to detect information system post-development change requests conflicts". Information Systems Frontiers, 14(5).

Reddy, K., Venter, H. S., Olivier, M. S. (2012). "Using time-driven activity-based costing to manage digital forensic readiness in large organizations". Information Systems Frontiers, 14(5).

Rodríguez-González, A., Colomo-Palacios, R., Guldris-Iglesias, F., Gómez-Berbís, J. M., García-Crespo, A. (2012). "FAST: Fundamental analysis support for financial statements. Using semantics for trading recommendations". Information Systems Frontiers, 14(5).

Zo, H., Nazareth, D. L., Jain, H. K. (2012). "End-to-end reliability of service oriented applications". Information Systems Frontiers, 14(5).
Ram Ramesh is a Professor and Chair of the Department of Management Science \& Systems in the School of Management at the State University of New York at Buffalo. His research streams include Economics of IT and Cloud Computing Markets, Database systems and Distributed Computing. He is a co-Editor-in-Chief of Information Systems Frontiers and serves on the editorial board of INFORMS Journal on Computing and many others.

Prof. H. Raghav Rao is a SUNY Distinguished Service Professor of MSS at UB, USA and WCU Visiting Professor of GSM at Sogang Univeristy, S. Korea. His interests are in the areas of management information systems, decision support systems, e-business, emergency response management systems and information assurance. He has also received the Fulbright fellowship in 2004. He is (or has been) a coeditor of a special issue of The Annals of Operations Research, the Communications of ACM, associate editor of Decision Support Systems, Information Systems Research and IEEE Transactions in Systems, Man and Cybernetics, and coEditor-in-Chief of Information Systems Frontiers and Guest Senior Editor at MISQ. Dr. Rao also has a courtesy appointment with Computer Science and Engineering as adjunct Professor. 